\title{
AL-NAKBA E A CONSTRUÇÃO DA PALESTINIDADE ${ }^{1}$
}

\section{AL-NAKBA AND THE COSTRUCTION OF THE PALESTINITY}

Bárbara Caramuru

Resumo: A Al-Nakba (A Catástrofe) foi um dos acontecimentos históricos marcantes na formação da identidade e subjetividade do indivíduo palestino. Ocorrida em maio de 1948, a partir da Guerra de Independência do Estado de Israel, fez com que um grande contigente de palestinos fosse forçado ao exílio, cerca de $80 \%$ da população. A partir desse processo, a identidade palestina se desenvolveu em meio a questões conflituosas envolvendo território, nação, etnia e martirização. A $A l-N a k b a$ é fundamental para o entendimento da "palestinidade" e como esta identidade é agenciada por tais atores sociais.

Palavras-chave: palestinos; identidade; nacionalismo.

Abstract: The Al-Nakba (The Catastrophe) was one of the most important historic facts that framed the identity and subjectivity of Palestinians. It happened in May 1948, during Israel's war of independence, and a huge contingent of Palestinians were forced to flee to exile, almost $80 \%$ of the total population. From this moment on, the Palestinian identity was developed among complex issues involving territory, nation, ethnics and martyrization. The Al-Nakba is

\footnotetext{
${ }^{1}$ Termo usado pelo Dr. Leonardo Schiocchet, para discutir o conceito do identidade palestina. Artigo intitulado: Uma Nação sem Estado: A Palestina dos Palestinos, 2015a.

${ }^{2} \mathrm{Na}$ época de submissão do artigo era aluna do $8^{\circ}$ período de História Licenciatura e Bacharelado na UFPR, orientada pelo Prof. Dr. Luis Roberto Braga Portella. Atualmente sou mestranda em Antropologia/UFPR, orientada pelo Prof. Dr. Lorenzo Gustavo Macagno. Meu lattes: http://lattes.cnpq.br/9925691058602976.
} 
fundamental to understand of the "palestinity" e how this identity is an agency of these social agents.

Keywords: palestinians; identity; nacionalism.

Neste artigo pretendo problematizar de que formas a Al-Nakba acessa e contribui na construção ${ }^{3}$ da identidade palestina. Pontualmente, os eventos que marcam o ano de 1948, no território da Palestina ficaram conhecidos, em termos nativos como $\mathrm{Al}-\mathrm{Nakba}$, a Catástrofe. Este foi o acontecimento histórico em que $80 \%$ da população palestina foi forçada ao exílio, tendo como marco inicial o dia 14 de maio de 1948, após a fundação do Estado de Israel. Esse evento foi decisivo, no que tange a construção de uma identidade do povo da Palestina, e se estabeleceu, de certa forma no relato contemporâneo, como uma espécie de novo mito de origem, da "palestinidade", ou seja, um resgate e potencialização do que vem a se configurar como "povo palestino". Sendo o sujeito desta construção identitária um indivíduo refém do exílio e do "tempo fora do tempo"'.

A partir desta leitura proponho que o sujeito de identidade palestina vive em um tempo suspenso. O exílio é o espaço de tempo em que, para não ser anulado, o refugiado busca reforçar sua identidade. (Schiocchet, 2015a) Porém, neste espaço em que existe o reforço do

\footnotetext{
${ }^{3}$ Utilizo o termo construção para falar de identidades a partir do entendimento que as identidades não são fixas, rígidas ou cristalizadas, mas que estão em constante processo de construção. Moldam-se a partir do processo dialético agenciado na relação entre o indivíduo, o fato social e a subjetividade derivada.

${ }^{4}$ Conceito de Lena Jayyusi, apud Schiocchet (2015).
} 
sofrimento e martirização deste agente, simultaneamente há uma exaltação de um passado glorioso mítico, o qual deve ser retomado, na sua forma moderna. E é a partir desta retomada que, no discurso nativo, o refugiado terá o direito de retorno à sua terra e sua civilização voltará supostamente ao esplêndido desenvolvimento que havia sido interrompido. Neste artigo, para além dos pontos citados, buscarei refletir sobre a influência dos conceitos de: nação e nacionalismo, suas implicações na construção da identidade do povo da Palestina, e a relação com as reivindicações e conflitos territoriais de ambos os povos: judeus e palestinos. Embora a proposta aqui colocada seja de caráter histórico e pautada em uma análise, especificamente, bibliográfica, alguns ecos das vozes do meu campo monográfico se fazem presentes. ${ }^{5}$

\section{A Al- Nakba no contexto histórico}

O termo Palaistine já fora usado em tempos remotos pelos gregos, posteriormente pelos romanos (Syria Palestina) e volta a ser utilizado "ocidentalmente" no período da Primeira Guerra Mundial pelos britânicos (período mandatário) (Schiocchet: 2015a). O território que compreende o que seria a Palestina histórica, inicialmente, foi uma

\footnotetext{
${ }^{5}$ Durante os anos de 2012 á 2014, realizei uma pesquisa etnográfica com alguns membros da Sociedade Muçulmana de Curitiba, visando discutir os processos de efervescência social vividos no Egito, no período recente, conhecidos como Primavera Árabe. A partir de um olhar local procurei analisar como este evento fora endossado pela comunidade local. Este campo, ainda que muito experimental, no ponto de vista teórico-metodológico, possibilitou-me acesso a tramas sociais e a agentes deste tecido social, complexo, dentre eles dois palestinos.
} 
terra de convívio comum a ambos os povos até a partilha realizada pela Organização das Nações Unidas - ONU - em 1947, que destinava aproximadamente $11.000 \mathrm{~km}^{2}$ para um milhão de palestinos e 14.000 $\mathrm{km}^{2}$ para 700.000 judeus.

Entre as diásporas do povo judaico, o território sempre esteve habitado por outros povos, dentre eles os árabes, como relata Hourani: “o interior da Síria, a região a oeste do Eufrates e o Tigre (a Jazira) eram de população em grande parte árabe. Eles trouxeram consigo o seu ethos e sua forma de organização social" (Hourani, 1991: 29). Desta forma, deve-se, todavia, complexificar os distintos discursos legitimadores, que se propõe a reivindicar um território a partir da temporalidade de ocupação, ou principalmente do discurso de origem. O que venho propor neste trabalho é problematizar a relação construída através da ideologia nacionalista entre território, povo e nação. Busco desta forma, também, desmistificar o slogan do projeto sionista: "uma terra sem povo para um povo sem terra", projeto do sionismo moderno, fundado pelo escritor austríaco Theodor Hertzl na segunda metade do século XIX na Europa. Com sua teoria exposta no livro Der Judenstaat (O Estado judeu), Hertzl propunha uma fuga ao anti-judaismo e a autonomia judaica a partir da criação de um estado étnico-religioso no território da palestina.

A partir de meados da década de 1920, com a proposta sionista de criar um "Lar Nacional Judeu" no território da Palestina, ocorreram migrações judaicas em massa para a região e a compra de terras em 
larga escala ${ }^{6}$. Potencializam-se, também, os conflitos entre árabes e judeus, uma insurreição dos povos nativos contra o projeto político sionista. Entre 1936-39 tais conflitos favorecem o desencadeamento da Grande Revolta Árabe, desencadeada por uma série de fatores, dentre eles, o assassinato do líder árabe Sheykh Izz Al-Din al-Qassam, em 1935. Esta revolta demostra a organização do povo árabe contra o sionismo e a dominação britânica, questionando a suposta crença de que eles não se encontravam organizados na luta pela autonomia e defesa de seu território.

Os conflitos árabe-judaicos inserem-se na polarização entre o Ocidente e o Oriente discutida por Edward Said (2007). O Orientalismo é um estilo de pensamento baseado numa distinção ontológica $e$ epistemológica (...)em suma, o Orientalismo como um estilo Ocidental para dominar, reestruturar e ter autoridade sobre o Oriente. (SAID, 1978, p.29). Ainda hoje a constituição política do chamado Oriente Médio é tem sido associada por veículos midiáticos e discursos políticos como antagônica a do "ocidente". Portanto o ator social desta região é ainda associado pela mídia global como: terrorista, fundamentalista religioso a-moderno. O oriente foi considerado, por seus colonizadores, e pelos adeptos desta política, inferior ao ocidente nas mais áreas diversas, tal como desenvolvimento cultural e civilizacional. Desta forma, legitimou-se o discurso, do colonialismo clássico, de que os

\footnotetext{
${ }^{6}$ Segundo Rashiod Khalid a venda de terra se dava na maioria dos casos por parte de proprietários de terra não palestinos, visto que, até o período o grande parte do povo palestino trabalhava a terra, servindo como mão de obra na agricultura para os proprietários de terras.
} 
povos do oriente não tinham capacidade suficiente de se autogovernar. Esta interpretação combinada ao Estado de Israel compor um estado novo com modelo diferenciado, politicamente, religiosamente e economicamente $^{7}$, dentro da região em virtude de sua constituição étnica, culminou em uma maior opressão aos palestinos após as vitórias de Israel, tanto diplomáticas quanto, e principalmente, no campo de guerra.

\section{A especificidade do nacionalismo israelense e a Diáspora Palestina}

Segundo o sociólogo Anthony Smith, em sua obra A Identidade Nacional (1991), existem duas formas de construção do nacionalismo que se apresentam como os maiores mitos identitários do mundo moderno: o nacionalismo étnico, caracterizado pelo autor como presente especialmente nos países europeus e o nacionalismo cívico, consolidado nos estados pós-coloniais. O estado de Israel, um estado criado no período histórico intitulado pós-colonial, ${ }^{8}$ emerge pautado em um nacionalismo étnico, tal qual o modelo europeu ocidental, somado a um

\footnotetext{
${ }^{7} \mathrm{O}$ Estado judaico, Israel, difere-se dos demais nos seguintes termos: politicamente este estado configura-se em um estado étnico. Sua formação ocorreu a partir da demanda de um estado para os nascidos de ventre judeu assim como para aqueles que se reconhecem enquanto judeus. Configurando-se, portanto, num Estado regido por uma determinação de caráter fundamentalmente religioso. Por fim, economicamente, este Estado efetiva um amplo diálogo com o imperialismo norte americano e com suas políticas econômicas, ao passo que mantém relações econômicas intrínsecas com a forma de capitalismo estadounidense, em oposição ao exemplo de seu irmão palestino.

${ }^{8}$ Uma especificidade no Estado de Israel é que, embora ele tenha sido criado no período histórico pós colonial, ele é caracterizado por um estado étnico, diferentemente dos demais estados pós coloniais.
} 
apoio político, econômico e bélico do estado Norte Americano. Tais fatores o destacam e diferenciam na região propiciando que alguns estados árabes se voltem contra Israel em uma luta por autonomia e soberania diante das relações de poder que vão se formando no Oriente Médio. Como exemplo, destaca-se a Guerra de 1967 ou Guerra dos Seis dias, em que a Liga dos Estados Árabes, fundada no Cairo em 1945 e movida pela ideologia do Pan-Arabismo de Gamal Nasser, enfrentou de maneira unificada o recente estado de Israel, porém, sem obter êxito.

A partir de 1948, com a, suposta, "Guerra de Independência" de Israel ou "Yom HaAtzmaut", evento que pelo povo Palestino fora denominado Al-Nakba, $80 \%$ da população palestina foi forçada a se retirar do território, abandonando seus lares, trabalhos, escolas e, em muitos casos, inclusive familiares, se deslocando a outros países, onde nem sempre foram bem acolhidos. Muitos destes palestinos foram deslocados para campos de refugiados, com péssimas condições de vida, o que inclui ausência de saneamento básico e fornecimento de água e comida. Além de estarem submetidos a restrição ou privação de trabalho, estudo, moradia, e ainda do direito de livre acesso e do direito de retorno previsto na resolução 194 da Organização das Nações Unidas - ONU.

De acordo com a Grassroots International e BADIL, por meio da Organização das Nações Unidas, é integrado a categoria de refugiado, palestino, todo indivíduo que residia no território da Palestina, no período mandatário, ou seja, dominação e colonização britânica, no período entre junho de 1946 até 15 de maio de 1948, e seus 
descendentes. Hoje essa população traduz cerca de, aproximadamente, 5 milhões de pessoas.

A partir de 1948 o enfrentamento do povo palestino com Israel passa a um momento mais crítico: com a consumação $d A$ Cátastrofe, ocorreu uma potencialização da "palestinidade". O sentimento de pertencimento nacional fomentou-se, principalmente, mas não somente, a partir do exílio - para além das experiências individuais - uma coletividade desenvolvida a partir das experiências sofridas nos processos de diáspora e refúgio. A identidade palestina, em determinados discursos, vinculou-se ao conceito de nacionalismo e de "civilidade", do direito a cidadania pertencente a um estado-nação, provenientes dos diálogos estabelecidos com a ideologia do colonizador europeu.

\section{Nacionalismos, conflitos étnicos e fronteiras}

Sobre o conceito de nacionalismo, para o historiador Eric J. Hobsbawm (1990), adquire um significado moderno apenas no fim do século XVIII, sendo que esta ideologia fundadora da nação possui um sentido ativo apenas se vinculada à ideia de estado territorial, EstadoNação.

Adaptando Hobsbawm, o estado vem a construir a nação. A nação, por sua vez, vem a constituir uma comunidade imaginada, citando Benedict Anderson (2008), embora estas comunidades configurem-se para aqueles que a tomam como objeto e a analisam como não reais - aqui me remeto a ideia de Anderson e ainda a proposta 
de Hobsbawm, a ideia de invenção de tradições no momento em que agem sobre o sujeito e, de certa forma, são incorporadas por estes, vem a agir sobre os indivíduos de forma a produzir um sentimento de vínculo coletivo e podendo vir a mobilizá-los ajustando as nações e aos estado modernos. (Hobsbawm, 2011: 58). A respeito da proposta de constituição do Estado moderno, cito Hobsbawm:

Enquanto os judeus espalhados pelo mundo por alguns milênios, nunca deixaram de se identificar a si mesmos, onde estivessem, como membros de um povo especial e distinto dos vários ramos de não crentes entre os quais viviam, em momento nenhum, ao menos desde o retorno do cativeiro babilônico, isto implicou uma aspiração séria por um estado político judeu - para não falar de um estado territorial - até que o nacionalismo judeu foi inventado no final do século XIX por analogia com o recém formado nacionalismo ocidental. (Hobsbawm, 2011:59-60)

A nação, para Mauss, seria uma reunião de fenômenos sociais, uma vida coletiva que se desenvolve dentro de grupos humanos, organismos políticos, passíveis de mudanças, porém, restritos a certa territorialidade, no que tange os fenômenos de civilização (Mauss, 1972). Esta combinação entre nacionalismo, nação, povo, língua e território, cria um significado específico para o refugiado palestino, que busca um conjunto de coisas que lhe foi tirado e que passa a tê-las como objeto de desejo. Desta forma, incorpora a ideologia nacionalista, o direito de se tornar parte de uma nação e de vincular-se aos territórios transpostos na luta palestina, fomentados por seu histórico de sofrimento.

Este nacionalismo, ao modo que se constrói, amplia o conflito, 
visto que destaca as diferenças entre os grupos antagonistas como meio de autoconstrução. De acordo com Mauss (1972), são "fronteiras criadas" a partir do contraste, da diferenciação, além de estabelecer patamares de superioridade. Vejamos esta citação:

"Os povos que falam tamil, no Ceilão, constituem uma nação
distinta da dos cingaleses pelos testes mais fundamentais da
existência das nações; em primeiro lugar, aquele que um passado
histórico diferenciado, na ilha, pelo menos tão antigo e glorioso
quanto o dos cingaleses(sic) e em segundo lugar pelo fato de
constituírem uma entidade linguística inteiramente distinta da dos
cingaleses, com uma insuperável herança clássica e um
desenvolvimento moderno da língua, que faz o tamil ser uma
língua inteiramente adequada para as presentes necessidades e
finalmente, pela razão de habitarem áreas territorialmente
definidas." (Ilanckai Tamil Arasu Kadchi Apud: Hobsbawm,
2011: 16)

A ideia de "palestinidade" se relaciona com os conceitos de nacionalidade, de território e de direitos cívicos, que se consolidam como os princípios de uma nação Palestina e que só fazem sentido a partir da formação de um Estado-Nação. Primeiramente, à luz de Schiocchet (2015a), a "palestinidade" é a soma de um conjunto de fatores identitários vinculados à causa palestina, ao direito a terra, ao direito de retorno segundo a resolução 194 da ONU e, no entendimento desta pesquisa, a experiência no exílio. Esses fatores reunidos compõem o que classifico como "sujeito palestino". Como nos relata Schiocchet, em 1928 os moradores da região passam a se apresentar aos mandatários britânicos reconhecendo-se coletivamente e intitulando-se palestinos mediante a migração judaica massiva e a pretensão sionista de posse do território em que eles residiam - Há, portanto, um reconhecimento e 
agenciamento identitário entre os indivíduos daquela região, que é notadamente potencializado conforme amplia-se o risco de perda de seu território e extinção de suas tradições. Cito:

"O evento marcado pelo termo é mais forte e sólido referente
informando um senso de palestinidade e, assim definindo parte
de uma noção de tempo palestina... A palestinidade, é gerada,
mantida e transformada em grande medida em relação ao
processo político que envolve a disputa territorial entre palestinos
e Israel. Assim, a nação palestina é hoje produzida e articulada
tanto nos escritórios dos partidos e movimentos políticos, quanto
o é nos escritórios de movimentos sociais populares, escritórios
de organizações humanitaristas internacionais, nas ruas dos
Territórios Ocupados ou dos campos de refugiados do Líbano da
Síria e da Jordânia, ou ainda de onde quer que estejam aqueles
que se veem como parte da nação palestina."'(Schiocchet, 2015:
8)

Certamente o processo de construção da identidade, tal como o de tradições, nos termos da Antropologia, não possuí um ponto específico como ponto de origem. Entretanto, trata-se de um processo longínquo e multifacetado em que se ressaltam demais processos. A partir da Nakba, há um reforço dessa construção identitária entre os indivíduos que vivenciaram tais processos. Essa construção do povo palestino como um grupo social auto-afirmado e que se reconhece de tal forma, de acordo com a ideologia nacionalista, pressupõe uma mesma língua, etnia, mito de origem comum, religião e território. Esta configuração, de Estado Nacional aos palestinos não foi definida devido à apropriação territorial, por guerra, consumada pelo estado de Israel, de grande parte das terras destinadas pela ONU ao estado da Palestina e do não reconhecimento do estado Palestino pelas demais organizações e instituições políticas. Esta 
noção engloba os elementos já citados, sendo estes os sustentadores da ideia de uma nação de cunho político, um Estado.

Quando foram orquestradas pelos mandatários franceses e britânicos, divisões territoriais, traçadas a partir de linhas imaginárias no pós-guerra, se sobrepuseram e ignoraram a vontade e divisão territorial em que se encontravam os povos do Oriente Médio previamente, privilegiando elites locais. Estas divisões foram naturalizadas com o passar dos anos por meio de discursos políticos, ideológicos e religiosos. A ideologia nacionalista faz parte da constituição deste território, atrelada à ideia de que uma nação se refere a um povo, uma língua, uma terra. Assim, foi estabelecido o recorte geográfico que culminou na formação dos Estados-Nação no Oriente Médio, exceto para aqueles que eram considerados, pelos britânicos e franceses, menos relevantes, ou mesmo "não-nações", tais como palestinos, curdos, entre outros grupos.

Stanley Tambiah (1993), caracteriza tais processos históricos como uma política étnico-religiosa fomentadora de conflitos. A proximidade entre ideologia, religião e a proposta de nacionalismo étnico atua como uma potencializadora de conflitos, tanto quanto as disputas entre etnias. Tal como defende Anthony Smith, a natureza multifacetada das nações inibe os direitos das minorias e o nacionalismo terminou por colocar uns aos outros em uma gama de conflitos (Smith, 1991).

A delimitação de fronteiras nacionais impostas por meio de processos colonialistas, bem como uma vida mantida sob tutela de entidades internacionais e de outras nações se configuram como um 
cenário de opressão e dominação. Conforme leis internacionais de direitos humanos, um agrupamento de pessoas entendido como povo, nação ou grupo étnico tem direito de retorno ao seu país, de acesso à cidadania e de garantia de meios de sobrevivência. Todavia, Mauss apresenta uma proposta que vai além do cosmopolitismo das nações, aquele que tende a destruir a nação como autoridade soberana e a consagraria a uma causa maior, a da humanidade (Mauss,1972:331). Em contrapartida ao cosmopolitismo ele apresenta uma segunda corrente, que não nega a nação, mas a situa. A proposta levantada por Mauss, do Internacionalismo, como um conjunto de ideias, sentimentos e regras que vem a dirigir poderia oferecer um caminho para ultrapassar relações entre as nações, entre as sociedades em geral, transcende-las (Mauss,1972:332). Uma proposta transnacional que supere as delimitações impostas pelas fronteiras territoriais e nacionais, bem como o nacionalismo cívico ou étnico, propondo um estado internacionalista como possível resolução para o conflito territorial palestino. Uma superação da ideologia nacionalista e sua aplicação prática, a criação da nação, vinculada ao patriotismo e a ideia de superioridade de uns para com os outros a partir do ressaltar das diferenças como meio de autoconstrução e separação. Tais processos seriam uma negativa à expansão pela força e à submissão de nações através da dominação na lógica imperialista, bem como seus desdobramentos.

\section{Conclusão}

Concluo, portanto, que a condição de refugiado, somada à 
experiência nos campos de refugiados, a resistência, a martirização dos mortos (não apenas de ativistas políticos, mas de todo aquele que se encontra na posição de resistência apenas pelo simples fato de existir, em tal condição) e o fato comum, a Al-Nakba, são fatores que colaboram na construção do que chamamos de identidade palestina. Identidade que teria por função primordial uni-los como povo e nação e sustentação da luta pelo direito ao território. Esta identidade palestina estaria vinculada também a um estilo de vida camponês, tendo em vista que no período de migração sionista e desencadeamento da "Catástrofe" a população palestina era majoritariamente rural e ligada fortemente à terra, a um território específico, um elemento fundamental, entre os demais, para a existência do sujeito camponês.

Uma exemplificação desta manobra de construção identitária, camponesa, é introduzida pela autora Sayigh (2007) ao relatar que o líder político Yasser Arafat, uma das mais conceituadas figuras da resistência palestina e a grande ${ }^{9}$ liderança da Organização para Libertação da Palestina (OLP), representou uma posição de reforço de uma identificação entre ser palestino e ser camponês, ou seja, de estar ligado à sua terra como meio de resistência e fortalecimento da cultura palestina, para que esta não fosse anulada em meio ao estado de exílio. Embora a identidade camponesa não se reduza apenas ao vínculo com a terra, Arafat usou o lenço da facção camponesa, de cor preta e branca, como um símbolo da Identidade Palestina. Estes usos icônicos mostram

\footnotetext{
${ }^{9}$ Adjetivos associados ao líder politico que foram expressos nas entrevistas que realizei com interlocutores palestinos durante o campo realizado na minha monografia em 2014.
} 
uma apropriação de um objeto para a finalidade que o historiador Hobsbawm denominaria de invenção de tradições (Hobsbawm, 2012) tendo em vista que, embora seja um objeto cotidiano, ele vem carregado de um valor simbólico diretamente ligado a subjetividade do indivíduo palestino. No momento em que esta liderança política faz uso de tal, afirma o vínculo do palestino com a terra, com o campo. Esta autoidentificação, de uma gama de palestinos, como camponeses se torna demasiadamente fundamental no momento em que a maior parte da população encontra-se em situação de exílio e na disputa pela propriedade da terra, ou ainda da instituição e reconhecimento político do estado palestino.

Tal como a construção desta identidade camponesa, a ideologia da nação é mais que um conceito: a criação dos Estados-nação neste território é causador de conflitos étnicos e religiosos, além de relacionar-se a identidades étnicas, conflitos políticos e territoriais, como os atuais entre Israel e Palestina. Tanto a nação quanto a religião, neste caso, veiculam-se a busca de um "ídolo das origens" que por sua vez, também vem a legitimar o direito a terra.

O nacionalismo enquanto ideologia atua diretamente sobre a subjetividade palestina, visto que com a incorporação do modelo político de Estado-Nação, nestas regiões fomenta-se a ideia de pertencimento nacional, território, fronteiras étnicas. $\mathrm{O}$ agente palestino, tal como os demais agentes que se viram submetidos a esta ideologia, são tomados por ela. O momento principal de formação do nacionalismo palestino, do pertencimento territorial e de autorreconhecimento 
identitário se deu ao longo do processo de disputa territorial, a partir da ocupação sionista. Foi potencializado no período aqui discutido. Este fenômeno histórico, específico, nomeado pelos povos de língua árabe como A Catástrofe, é parte fundamental para o entendimento da palestinidade, ou seja, da subjetividade que atua na formação da identidade do agente social palestino. Mostrando-se de forma nítida no momento em que este sujeito relaciona seu mundo interno com o externo, expondo o seu íntimo e as raízes na qual ele se fundamenta.

A Al-Nakba, se encarada como um novo mito de origem, é utilizada como ponto substancial para a sustentação identitária do "sujeito palestino". Embora nos relatos recebidos, por parte de alguns agentes palestinos, esta construção identitária tenha seu mito de origem, principal, fundamentado em estudos da filologia, relatos de ocupação territorial, pautados na história e ainda fundamentada nos relatos religiosos. Todavia, deve ser considerada a seguinte perspectiva: embora as identidades sejam construídas neste processo, sendo este agente ativo no processo dialogando nesta construção, no momento em que esta identidade é construída e internalizada pelo sujeito e ainda refletida na ação e na prática cotidiana, ou seja ela é agenciada, ela é real. A relação entre agente e identidade se dá no plano da construção e no plano da realidade, que não devem ser dicotomizados, visto que para o sujeito atuante na identidade e para os observadores externos esta construção é real, portanto é legitima. A Al-Nakba é a catástrofe que permeia a vida de todo aquele nascido na Palestina, ou que se encontra na condição de refugiado, o que, segundo os critérios utilizados pela ONU, engloba 
também os descendentes dos exilados: cerca de cinco milhões de pessoas que se reconhecem e constroem sua intersubjetividade a partir da identificação de sofrimento gerado por este fato. Estes que para além do fato em si, vivem a espera da superação da Catástrofe, da volta ao lar, do direito de retorno, do direito a terra e, essencialmente, do direito à vida.

\section{Referências bibliográficas}

ANDERSEN, Benedict. Comunidades Imaginadas: reflexões sobre origem e a difusão do nacionalismo. São Paulo: Companhia das Letras, 2008.

HOBSBAWM, Eric. Nações e Nacionalismo desde 1780. Rio de Janeiro: Saraiva, 2011.

HOBSBAWM, Eric; RANGER, Terence. A Invenção das Tradições. São Paulo: Paz e Terra, 2012.

HOURANI, Albert. Uma história dos povos árabes. São Paulo: Companhia das letras, 2006.

MAUSS, Marcel. Sociedade y Ciencias Sociales, Barcelona Editores, 1972.

Paulo. 1913

. Notas sobre civilização, 12. Anné de Sociologique. São

SAID, Edward. A questão da Palestina. São Paulo. Unesp, 2012.

. Orientalismo: o ocidente como invenção do ocidente. São Paulo: Companhia das Letras, 2007.

SAYIGH, Rosemary. The Palestinians: From Peasants to 
Revolutionaries. London: Zed Books, 2007.

SCHIOCCHET, Leonardo.(Accepted for publication. Forthcoming, Summer 2015). Uma Nação sem Estado: A Palestina dos Palestinos [A Stateless Nation: The Palestine os the Palestinians] in LIMONCIC, Flávio \& MARTINHO, Francisco. Nações [Nations]. a

- (Manuscript complete, to be submitted in May de 2015). The Least of The Undersirables: 117 Palestinian refugees in Brazil between Humanitarism and Nationalism. In: The Journal of Palestine Studies. b

SMITH, Anthony. National Identies. Reno: University of Nevada Press, 1991.

STANLEY, Tambiah. Leveling Crowds: Ethnonacionalist Conflicts and Colletive Violence in South Asia. Los Angeles. University os Califórnia Press, 1993.

Recebido em: 27/05/2014 Aceito em: 13/05/2014 